\title{
CCS-MPC for PMSM with Wide Speed Range based on Variable DC-Bus Voltage Control applied to the Flywheel Energy Storage System
}

\author{
Aobo Tian ${ }^{1}$, Congzhe Gao ${ }^{1, *}$ Jingliang $\mathrm{Lv}^{2}$ and XinJian Jiang ${ }^{2}$ \\ ${ }^{1}$ Beijing Institute of Technology, Beijing, China \\ ${ }^{2}$ Tsinghua University, Beijing, China
}

\begin{abstract}
In this paper, in order to verify the effect of variable DC-bus voltage control, CCS-MPC (Continuous-Control-Set MPC) control is used to research the control of PMSM (Permanent-Magnet Synchronous Machine) in a wide speed range. In order to maximize the speed of PMSM, the MTPA control, the field weakening control and the variable DC-bus voltage control are applied in the different speed range of PMSM. CCS-MPC can eliminate the control delay by controlling the predicted step size. When CCSMPC is applied to the PMSM control with a wide speed range, the advantages of strong adaptability of CCS-MPC can be exerted.
\end{abstract}

\section{Introduction}

Flywheel energy storage has many advantages, such as high efficiency, no pollution and simple maintenance. Renewable energy generation and micro-grid technology have promoted the application of AC-DC hybrid grid. Time-varying loads and fluctuating renewable energy will lead to the fluctuation of power and voltage in the DC grid. Using flywheel energy storage can realize the stable regulation of power and voltage in the DC grid. The flywheel energy storage which covers a wide speed range is a research hotspot in recent years. PMSM has good adaptability in flywheel energy storage system.

In the field of PMSM with wide speed range, the most commonly used control strategies include MTPA control [1]-[2] and field weakening control [3] which can improve the operation efficiency and speed range of PMSM.

MPC of PMSM can be divided into CCS-MPC (Continuous Control-Set MPC) [4]-[5] and FCS-MPC (Finite-Control-Set MPC) [6]-[7] according to the different control methods of its voltage vectors.

The output of CCS-MPC is the voltage vector, which needs to pass through the PWM modulation module to achieve the purpose of controlling PMSM.

During the predictive control of FCS-MPC, it traverses the switch combination states of all control circuits, submits the control objectives and constraints of the system into the evaluation function for calculation, obtains the optimal switch combination voltage vector through comparison, and outputs the switch combination directly to drive circuit of the switches.

In [8], an improved continuous-time model predictive control of PMSM for a wide-speed range, including the constant torque region and the fluxweakening $(\mathrm{FW})$ region.

In [9], by using the multi-step predictive MPC control method, a better switching combination can be obtained with reduced torque and current fluctuations

In [10], when solving the cost function, the switching process of switch combination is constrained, which reduces the solving process of the cost function and improves the control period of multi-step MPC prediction

In this paper, variable DC-bus voltage control of PMSM based on model predictive control is proposed. In the section II, the system topology and mathematical model are introduced. In the section III, the control strategy which contain the field weakening control, variable DC-bus voltage control and CCS-MPC is introduced. In the section IV, the effectiveness of the variable bus control strategy is verified with the simulation results. In the section $\mathrm{V}$, the conclusion is obtained.

\section{Analysis of the converter}

The system circuit is shown in Figure 1. Power of the system can flow in bidirection directions. The system contains three-phase half bridge converter circuit and half bridge circuit 2 parts.

The system can realize bidirection power flow. When the system operates in the state of rectification, the threephase converter circuit converts the $\mathrm{AC}$ to $\mathrm{DC}$ at the motor side, and the half-bridge circuit operates in the step-down mode to supply power to the DC microgrid. When the system absorbs energy from the microgrid, the half-bridge circuit operates in the boost mode.

* Corresponding author: gcz_fly@163.com 


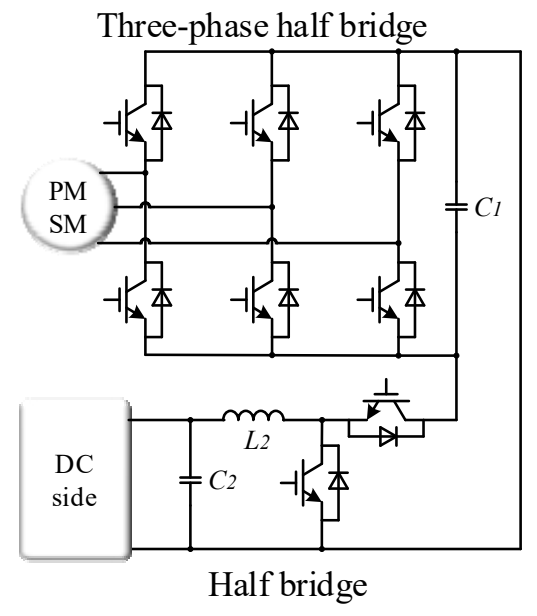

Figure. 1 System circuit

\subsection{Three-phase converter circuit}

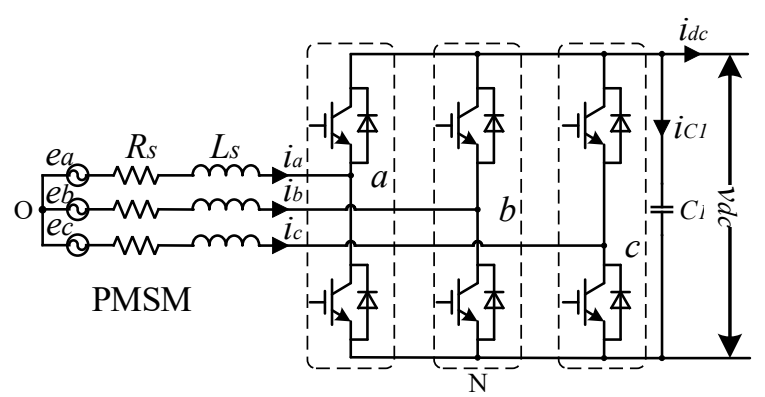

Figure. 2 Three-phase bridge circuit

The topology of three-phase converter bridge is shown in Figure. 2. The internal model of permanent magnet motor is replaced by $e$ (Counter electromotive force), $R_{S}$ (internal resistance) and $L_{S}$ (inductance). $\mathrm{O}$ is the neutral point of the star connection motor. $\mathrm{N}$ is the negative pole of the DC bus. According to the circuit topology, the mathematical model can be listed as follows:

$$
\left\{\begin{array}{l}
L_{s} \frac{d i_{a}}{d t}+R_{s} i_{a}=e_{a}-\left(v_{a N}+v_{N O}\right) \\
L_{s} \frac{d i_{b}}{d t}+R_{s} i_{b}=e_{b}-\left(v_{b N}+v_{N O}\right) \\
L_{s} \frac{d i_{c}}{d t}+R_{s} i_{c}=e_{c}-\left(v_{c N}+v_{N O}\right)
\end{array}\right.
$$

The three-phase converter bridge is composed of six switches on three bridge arms, and the binary switching logic function $s_{k}$ is defined:

$$
s_{k}=\left\{\begin{array}{l}
1 \\
0
\end{array}(k=a, b, c)\right.
$$

When $s_{k}=1$, the power switch of the upper bridge turns on and the power switch of the lower bridge arm turns off.

When $s_{k}=0$, the power switch of the upper bridge turns off and the power switch of the lower bridge arm turns on.

Considering $\mathrm{ABC}$ three-phase switching state, the following can be obtained:

$$
\left\{\begin{array}{l}
v_{a N}=v_{d c} s_{a} \\
v_{b N}=v_{d c} s_{b} \\
v_{c N}=v_{d c} s_{c}
\end{array}\right.
$$

Constraint conditions of three-phase current is:

$$
i_{a}+i_{b}+i_{c}=0
$$

Substituting (3) and (4) into (1), we can get:

$$
v_{N O}=-\frac{v_{d c}}{3} \sum_{k=a, b, c} s_{k}
$$

Substituting (3) and (5) into (1), we can get:

$$
\left\{\begin{array}{l}
L_{s} \frac{d i_{a}}{d t}+R_{s} i_{a}=e_{a}-\left(v_{d c} s_{a}-\frac{v_{d c}}{3} \sum_{k=a, b, c} s_{k}\right) \\
L_{s} \frac{d i_{b}}{d t}+R_{s} i_{b}=e_{b}-\left(v_{d c} s_{b}-\frac{v_{d c}}{3} \sum_{k=a, b, c} s_{k}\right) \\
L_{s} \frac{d i_{c}}{d t}+R_{s} i_{c}=e_{c}-\left(v_{d c} s_{c}-\frac{v_{d c}}{3} \sum_{k=a, b, c} s_{k}\right)
\end{array}\right.
$$

(6) can be rewritten in rotating frame as follows:

$$
\left\{\begin{array}{l}
L_{s} \frac{d i_{d}}{d t}=e_{d}-R_{s} i_{d}+\omega_{e} L_{q} i_{q}-v_{d c} s_{d} \\
L_{s} \frac{d i_{q}}{d t}=e_{q}-R_{s} i_{q}-\omega_{e} L_{d} i_{d}-v_{d c} s_{q}
\end{array}\right.
$$

where $S_{d}$ and $S_{q}$ are the switching functions in the rotating frame. $\omega_{e}$ is the speed of PMSM. $e_{d}$ and $e_{q}$ are the electromotive force.

The DC side current satisfies the formula:

$$
C_{1} \frac{d v_{d c}}{d t}=\frac{3}{2}\left(s_{d} i_{d}+s_{q} i_{q}\right)-i_{d c}
$$

Similarly, the mathematical model of PMSM is as follows:

$$
\left\{\begin{array}{l}
L_{s} \frac{d i_{d}}{d t}=-u_{d}-R_{s} i_{d}+\omega_{e} L_{q} i_{q} \\
L_{s} \frac{d i_{q}}{d t}=\omega_{e} \Psi_{f}-u_{d}-R_{s} i_{q}-\omega_{e} L_{d} i_{d}
\end{array}\right.
$$

where $u_{d}$ and $u_{q}$ are the terminal voltages of PMSM. $\psi_{f}$ is the flux linkage of PMSM.

\subsection{Half bridge circuit}

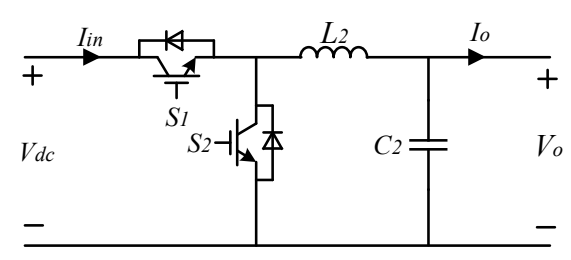

Figure. 3 Half bridge circuit

The topology of half bridge circuit is shown in the Figure 3. When the half-bridge circuit operates in the state of bidirectional power flow, the PWM signals of $S_{1}$ and $S_{2}$ are complementary, and the four operating modes are shown in the Figure 4. 


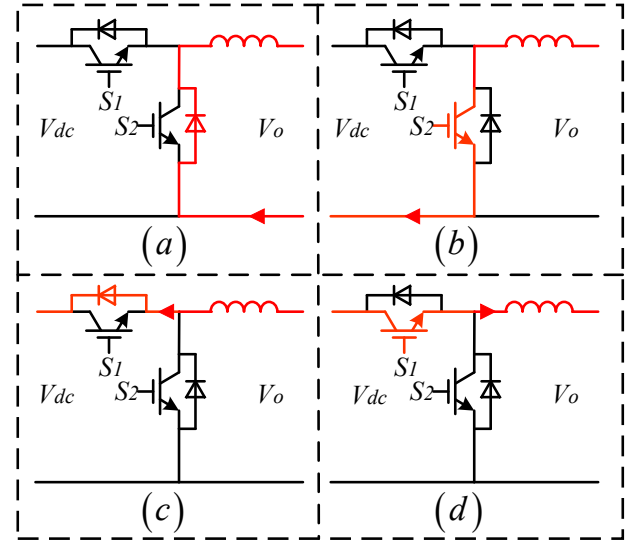

Figure. 4 The 4 operating modes (a) (b) (c) (d)

Since the switching signals of $S_{1}$ and $S_{2}$ are complementary, a switching cycle can be divided into two parts for discussion:

When $S_{I}$ is turned on, the inductance current flows in a positive direction, as shown in Figure. 4(d). When $S_{l}$ is off, the current continues through a diode, as shown in Figure. 4(a). When $S_{2}$ is turned on, the inductance current flows in the opposite direction, as shown in Figure. 4(b). When $S_{2}$ is off, the current continues through a diode, as shown in Figure.4(c). By using complementary PWM signal to control the half bridge circuit, the bidirectional fluidity of power flow is realized. When the flywheel system operates in generation mode, the direction of power flow is forward. When the flywheel system operates in motor mode, the power flow is opposite.

\section{Control algorithms}

\subsection{The field weakening control}

In order to increase the speed of the PMSM after it reaches the voltage limit, the field weakening current is injected into the $i_{d}$ axis to offset the increased voltage of PMSM with the speed increasing. The principle of the field weakening control is shown in the Figure 5.

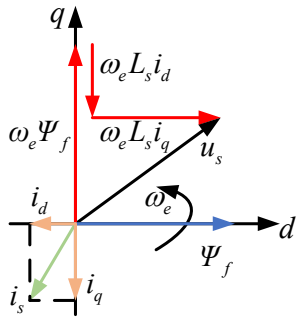

Figure.5 Current vector diagram of field weakening control

$u_{s}$ is the motor voltage. As the speed $\omega_{e}$ increasing, the amplitude of $u_{s}$ increases. When the field weakening current $i_{d}$ is injected, the amplitude of $u_{s}$ can be reduced and the speed can be increased.

The field weakening current can be obtained by:

$$
\left(L_{s} i_{d}+\Psi_{f}\right)^{2}+\left(L_{s} i_{q}\right)^{2}=\left(\frac{U_{s \max }}{\omega_{e}}\right)^{2}
$$

\subsection{The variable DC-bus voltage control}

The voltage boundary formula of the motor can be written as:

$$
V_{d c} \geq m_{1} \sqrt{\left(\left(\omega_{e} L_{s} i_{q}\right)^{2}+\left(\omega_{e} \psi_{f}-\omega_{e} L_{s} i_{d}\right)^{2}\right)}
$$

where $m_{1}$ is the utilization rate of DC bus voltage. Ignoring loss, motor output power can be written as:

$$
P=\frac{3}{2}\left(u_{d} i_{d}+u_{q} i_{q}\right)=\frac{3}{2} \omega_{e} \psi_{f} i_{q}
$$

According to power conservation, the output power of the motor is equal to the load power of the half bridge circuit. The formula can be listed as follows:

$$
\frac{3}{2} \omega_{e} \psi_{f} i_{q} \approx \frac{V_{\mathrm{o}}^{2}}{R_{\mathrm{LD}}}=M
$$

$M$ is the load power. $i_{q}$ can be expressed as:

$$
i_{q}=\frac{2 M}{3 \omega_{e} \psi_{f}}
$$

The voltage boundary equation can be written as:

$$
V_{d c}^{2} \geq m_{1}^{2}\left(\omega_{e}^{2}\left(\psi_{f}-L_{s} i_{d}\right)^{2}+\frac{4 M^{2} L_{s}^{2}}{9 \psi_{f}^{2}}\right)
$$

The equation can be rewritten into the hyperbolic equation form of $V_{d c}$ and $\omega_{e}$ :

$$
\frac{V_{d c}^{2}}{m_{1}^{2}\left(\psi_{f}-L_{s} i_{d}\right)^{2}}-\frac{\omega_{e}^{2}}{1}=\frac{4 M^{2} L_{q}^{2}}{9 \psi_{f}^{2}\left(\psi_{f}-L_{s} i_{d}\right)^{2}}
$$

When the PMSM is operating at high speed, hyperbolic asymptotes can be used to express the relationship between $V_{d c}$ and $\omega_{e}$, its expression is as follows:

$$
\omega_{e}= \pm \frac{1}{\mathrm{~m}_{1}\left|\psi_{f}-L_{s} i_{d}\right|} V_{d c}
$$

The relationship between the speed $\omega_{e}$ and the bus voltage $V_{d c}$ can be used in the process of speed-up. High accuracy can be obtained by using (19). Formula (20) can be used when the calculation is simplified. Both of the two methods can realize variable DC-bus voltage control.

At the end of the variable DC-bus voltage control, $V_{\text {var-max }}$ is set for the voltage limit of circuit.

\subsection{CCS-MPC}

The time delay between the controller and the drive circuit is shown in the figure 6 .

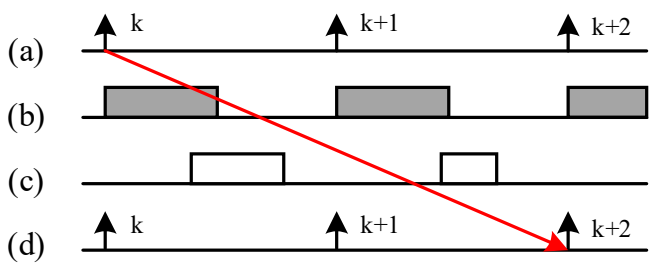

Figure.6 Time delay graph

Fig. 6(a) represents the controller period, and time $\mathrm{k}$ is the present time; Fig. 6(b) shows the calculation process of the controller, and the shaded part is the 
calculation time; Figure 6(c) shows the PWM of the drive. Figure 6(d) shows the effect of the control. According to the observation, the control system has two periods of control delay.

The predicted value at the time $\mathrm{k}+1$ can be expressed as:

$$
\left\{\begin{aligned}
i_{d m}(k+1)= & \left(1-\frac{T_{s} R_{s}}{L_{s}}\right) i_{d}(k)+\frac{T_{s}}{L_{s}} u_{d}(k) \\
& +T_{s} \omega_{e} i_{q}(k) \\
i_{q m}(k+1)= & \left(1-\frac{T_{s} R_{s}}{L_{s}}\right) i_{q}(k)+\frac{T_{s}}{L_{s}} u_{q}(k) \\
& -T_{s} \omega_{e} i_{d}(k)-\frac{T_{s} \omega_{e} \psi_{f}}{L_{s}}
\end{aligned}\right.
$$

Through iteration, we can get the predicted value of $\mathrm{k}+2$ as follows:

$$
\left\{\begin{aligned}
i_{d m}(k+2)= & \frac{L_{s}-T_{s} R_{s}}{L_{s}} i_{d m}(k+1)+\frac{T_{s}}{L_{s}} u_{d}(k+1) \\
& +T_{s} \omega i_{q m}(k+1) \\
i_{q m}(k+2)= & \frac{L_{s}-T_{s} R_{s}}{L_{s}} i_{q m}(k+1)+\frac{T_{s}}{L_{s}} u_{q}(k+1) \\
& -T_{s} \omega i_{d m}(k+1)-\frac{T_{s} \omega \psi_{f}}{L_{s}}
\end{aligned}\right.
$$

In each predicted step, there is an error Ek, which can be expressed as:

$$
\left\{\begin{array}{l}
e(k+1)=i_{M}(k+1)-i_{m}(k+1)=i(k)-i_{m}(k) \\
e(k+2)=i_{M}(k+2)-i_{m}(k+2)=i(k)-i_{m}(k) \\
\vdots \\
e(k+P)=i_{M}(k+P)-i_{m}(k+P)=i(k)-i_{m}(k)
\end{array}\right.
$$

By adding the error into the prediction model, the predicted value of current can be obtained as follows:

$$
\left\{\begin{array}{l}
i_{d M}(k+2)=i_{d m}(k+2)+e_{d}(k+2) \\
i_{q M}(k+2)=i_{q m}(k+2)+e_{q}(k+2)
\end{array}\right.
$$

After predicting the current at time $\mathrm{k}+2$, The current meets: $i_{d M}(k+2)=i_{d}{ }^{r e f}, i_{q M}(k+2)=i_{q}{ }^{r e f}$. Substituting the predicted value of current into formula $A$, the predicted value of voltage can be obtained as:

$$
\left\{\begin{array}{l}
u_{d}(k+1)=\frac{L_{s}}{T_{s}}\left[\begin{array}{l}
i_{\text {dref }}-\left(1-\frac{T_{s} R_{s}}{L_{s}}\right) i_{d m}(k+1) \\
-T_{s} \omega_{e} i_{q m}(k+1)-e_{d}(k+2)
\end{array}\right] \\
u_{q}(k+1)=\frac{L_{s}}{T_{s}}\left[\begin{array}{l}
i_{q r e f}-\left(1-\frac{T_{s} R_{s}}{L_{s}}\right) i_{q m}(k+1) \\
-T_{s} \omega_{e} i_{d m}(k+1)-\frac{T_{s} \omega_{e} \psi_{f}}{L_{s}} \\
-e_{q}(k+2)
\end{array}\right]
\end{array}\right.
$$

In order to prevent the voltage amplitude from exceeding the maximum value of $1 / 3 \mathrm{UDC}$, the amplitude transformation of the predicted voltage is carried out. The transformation formula is as follows:

$$
\left\{\begin{array}{l}
u_{d}^{*}=\frac{u_{d}(k+1)}{\sqrt{u_{d}^{2}(k+1)+u_{q}^{2}(k+1)}} \frac{U_{d c}}{\sqrt{3}} \\
u_{q}^{*}=\frac{u_{q}(k+1)}{\sqrt{u_{d}^{2}(k+1)+u_{q}^{2}(k+1)}} \frac{U_{d c}}{\sqrt{3}}
\end{array}\right.
$$

The program flow chart of model predictive control is shown in the figure 7.

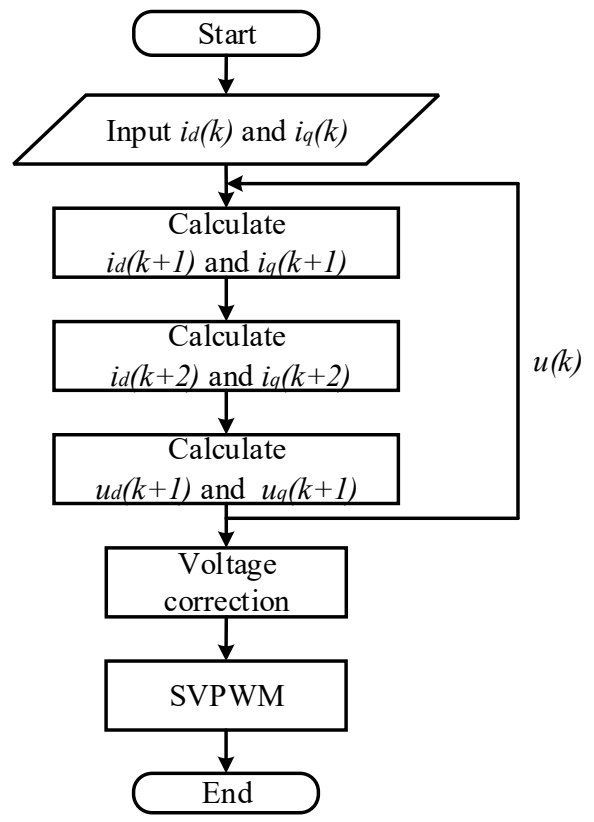

Figure.7 The flow chart of CCS-MPC

\subsection{CCS-MPC with the field weakening control and the variable DC-bus voltage control}

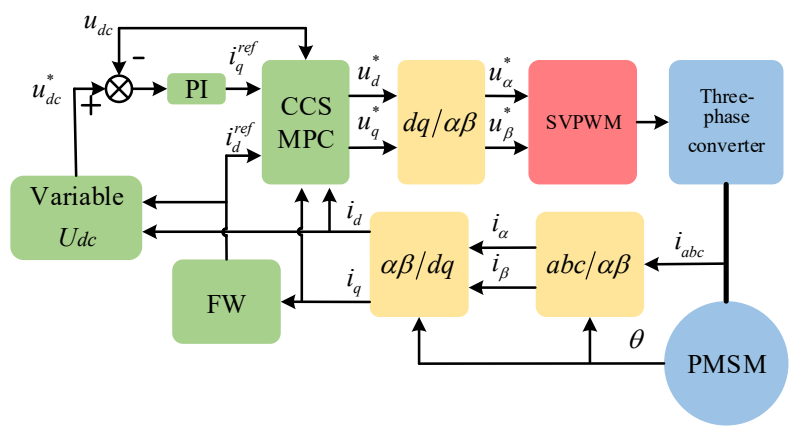

Figure.8 Control block diagram of CCS-MPC (including fielding weakening control and variable DC-bus voltage control)

The control system block diagram is as shown in the Figure.8. The main circuit of the PMSM control system includes three-phase half bridge and PMSM. The carrier modulation mode is SVPWM, the voltage controller is $\mathrm{PI}$, and the current controller is CCS-MPC.

The starting control strategy of PMSM is $i_{d}=0$; When the speed of PMSM increases, the control system adopts the field weakening control and the variable DC-bus voltage control strategy. 


\section{Simulation results}

In order to verify the control effect of the variable DCbus voltage control and the fielding weakening control under CCS-MPC, simulation analysis is carried out.

The main parameters of the three-phase bridge circuit, half-bridge circuit and PMSM are shown in the Table I, Table II and Table III.

TABLE I. PARAMETERS OF THREE PHASE CONVERTER CIRCUIT

\begin{tabular}{ccc}
\hline Items & Symbol & Values \\
\hline Output Voltage & $V_{d c}$ & $400 \mathrm{~V}$ \\
$\begin{array}{c}\text { Switching } \\
\text { frequency } \\
\begin{array}{c}\text { Voltage } \\
\text { capacitance }\end{array}\end{array} F_{s I}$ & $10 \mathrm{kHz}$ \\
\hline
\end{tabular}

TABLE II. PARAMETERS OF HALF-BRIDGE CiRCUIT

\begin{tabular}{ccc}
\hline Items & Symbol & Values \\
\hline Input Voltage & $V_{d c}$ & $400 \mathrm{~V}$ \\
Output Voltage & $V_{o}$ & $200 \mathrm{~V}$ \\
Inductance & $L_{2}$ & $2 \mathrm{mH}$ \\
Capacitance & $C_{2}$ & $6.8 \mathrm{mF}$ \\
Switching & & \\
frequency & $F_{s 2}$ & $10 \mathrm{kHz}$ \\
\hline
\end{tabular}

TABLE III. PARAMETERS OF PERMANENT MAGNET MOTOR

\begin{tabular}{ccc}
\hline Items & Symbol & Values \\
\hline Pole pairs & $p$ & 4 \\
Armature & & $2 \mathrm{mH}$ \\
inductance & $L S$ & \\
$\begin{array}{c}\text { Stator phase } \\
\text { resistance }\end{array}$ & $R_{S}$ & $0.2 \Omega$ \\
Flux linkage & $\Psi_{f}$ & $0.2(\mathrm{~V} \cdot \mathrm{s})$ \\
\hline
\end{tabular}

The speed of PMSM can be improved by both the field weakening control and variable DC-bus voltage control. In order to obtain the maximum speed range, both the field weakening control and the variable DCbus voltage control are used during the process of speedup. MTPA $\left(i_{d}=0\right)$ control is used at the start of PMSM. The field weakening control is used at the time MTPA control reaches the limit. When the field weakening control reaches the maximum, the variable DC-bus voltage control is used.

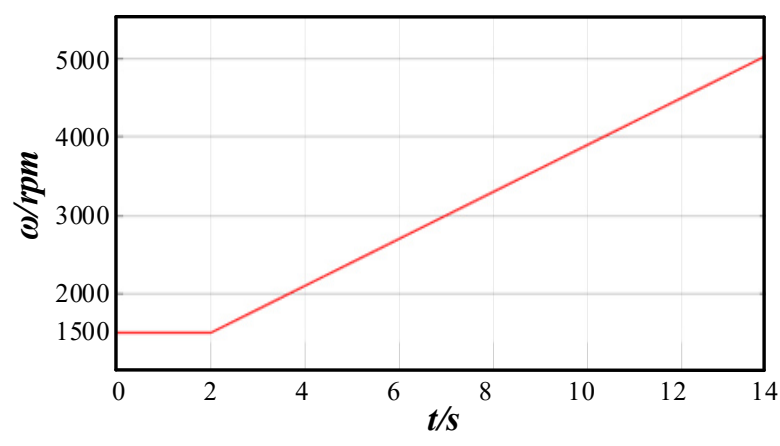

Figure.9 PMSM Speed

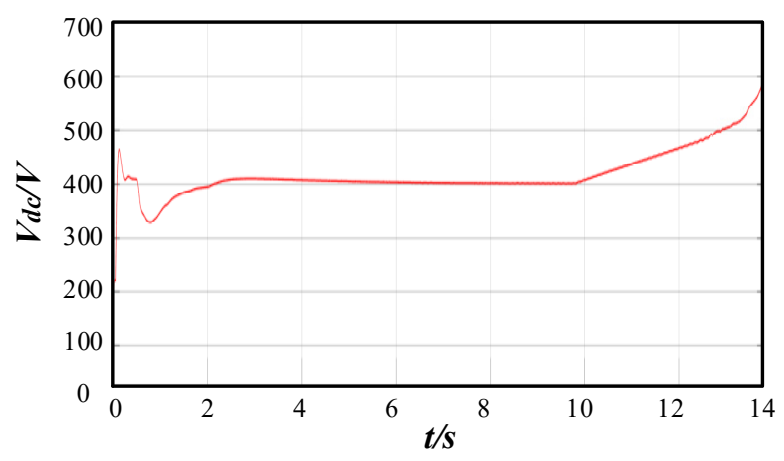

Figure.10 DC-BUS Voltage

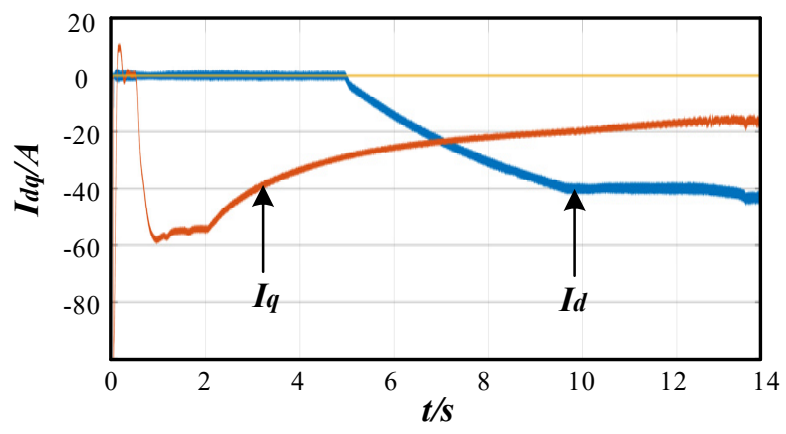

Figure.11 The PMSM currents

According to Figure 9 and Figure 11, the control of PMSM is MTPA $\left(i_{d}=0\right)$ control in $0 \mathrm{~s}-5 \mathrm{~s}$, and the speed of PMSM rises from 0 to $2500 \mathrm{rpm} / \mathrm{min}$.

In $4 \mathrm{~s}-10 \mathrm{~s}$, the PMSM is under the field weakening control, and the speed of PMSM increases from $2500 \mathrm{rpm} / \mathrm{min}$ to $3900 \mathrm{rpm} / \mathrm{min}$.

In $10 \mathrm{~s}-14 \mathrm{~s}$, the variable DC-bus voltage control is used, the bus voltage rises from $400 \mathrm{~V}$ to $570 \mathrm{~V}$, as is shown in Figure 10. The speed of PMSM rises from $3900 \mathrm{rpm}$ to $5000 \mathrm{rpm}$.

According to Fig. 11, the current ripple size is $3 \mathrm{~A}$.

\section{Conclusion}

A variable bus voltage control strategy is proposed. Through theoretical derivation and simulation verification, the variable DC-bus voltage control can significantly increase the maximum speed of PMSM.

CCS-MPC is applied in the control of PMSM with wide speed range, the variable DC-bus voltage control and the fielding weakening control are used to realize the operation of PMSM with wide speed range. 


\section{Acknowledgment}

This work is supported by the National Key Research and Development Program of China (Grant No. 2018YFB0905500)

\section{References}

1. G. Foo and M. F. Rahman, "Sensorless SlidingMode MTPA Control of an IPM Synchronous Motor Drive Using a Sliding-Mode Observer and HF Signal Injection," in IEEE Transactions on Industrial Electronics, vol. 57, no. 4, pp. 1270-1278, April 2010, doi: 10.1109/TIE.2009.2030820.

2. S. Ekanayake, R. Dutta, M. F. Rahman, D. Xiao and J. Fletcher, "Operation along the maximum torque per voltage trajectory in a direct torque and flux controlled interior permanent magnet synchronous motor," 8th IET International Conference on Power Electronics, Machines and Drives (PEMD 2016), Glasgow, UK, 2016, pp. 1-6, doi: 10.1049/cp.2016.0326.

3. F. Giulii Capponi, R. Terrigi, F. Caricchi and L. Del Ferraro, "Active Output Voltage Regulation for an Ironless Axial-Flux PM Automotive Alternator With Electromechanical Flux Weakening," in IEEE Transactions on Industry Applications, vol. 45, no. 5, pp. 1785-1793, Sept.-oct. 2009, doi: 10.1109/TIA.2009.2027552.

4. K. Belda and D. Vošmik, "Explicit Generalized Predictive Control of Speed and Position of PMSM Drives," in IEEE Transactions on Industrial Electronics, vol. 63, no. 6, pp. 3889-3896, June 2016, doi: 10.1109/TIE.2016.2515061.

5. M. Preindl and S. Bolognani, "Comparison of direct and PWM model predictive control for power electronic and drive systems," 2013 Twenty-Eighth Annual IEEE Applied Power Electronics Conference and Exposition (APEC), 2013, pp. 2526-2533, doi: 10.1109/APEC.2013. 6520651.

6. Kennel R M , Kazmierkowski M, Rodriguez J , et al. Predictive control in power electronics and drives[C]// IEEE International Symposium on Industrial Electronics. IEEE, 2008.

7. Kouro S, Cortes P, Vargas R, et al. Model Predictive Control-A Simple and Powerful Method to Control Power Converters[J]. IEEE Transactions on Industrial Electronics, 2009, 56(6):1826-1838.

8. Errouissi R, Al-Durra A, Muyeen S M, et al. Continuous-time model predictive control of a permanent magnet synchronous motor drive with disturbance decoupling[J]. Iet Electric Power Applications, 2017, 11(5):697-706.

9. Geyer T . A comparison of control and modulation schemes for medium-voltage drives: Emerging predictive control concepts versus Field Oriented Control $[\mathrm{C}] / / 2010$ IEEE Energy Conversion Congress and Exposition. IEEE, 2010.
10. Scoltock J, Geyer T, Ma Da Wala U . A comparison of Predictive Current Control schemes for MV induction motor drives[C]// IECON 2011 37 th Annual Conference of the IEEE Industrial Electronics Society. IEEE, 2012. 